\title{
Pathomorphological Findings of White Line Disease with Digital and Inner Organ Infections in Culling Dairy Cows
}

\author{
${ }^{1}$ Mohsen Nouri, ${ }^{1}$ Iradj Nowrouzian, \\ ${ }^{2}$ Seyyed Hossein Marjanmehr, ${ }^{1}$ Alireza Vajhi and ${ }^{1}$ Davoud Faskhoudi \\ ${ }^{1}$ Department of Clinical Sciences, \\ ${ }^{2}$ Department of Pathology, \\ Faculty of Veterinary Medicine, The University of Tehran, P.O. Box 14195-181, Tehran, Iran
}

Received 2013-02-11, Revised 2013-04-19; Accepted 2013-08-20

\begin{abstract}
The aim of this study was to investigate pathomorphological findings of white line disease in culling lame cows, with special reference to the lesions and their distribution. The most prominent pathomorphologic findings of the claw with white line disease included extensor process entheseophyte $(75.0 \%)$, flexor tuberisity entheseophyte (37.5\%) and abaxial margin bone absorption (68.7\%). Six out of the total of WLD3 cases had osteolysis of flexor tuberisity $(66.7 \%)$. In WLD3 cases, three out of the total of 9 cases showed septic osteoarthritis in distal inter-phalangeal joint (33.3\%). Ankylosis was observed only in one case between P3 bone and distal sesamoid bone. One of case with WLD2 showed severe bone sequestration of P3 bone. Laminitis may have affected virtually this case at some previous time. Routine trimming and scoring of locomotion seems to provide suitable parameters for early diagnosis and prevention of premature culling in dairy cows.
\end{abstract}

Keywords: Lameness, Laminitis, Deep Sepsis, White Line Disease, P3 Bone

\section{INTRODUCTION}

White Line Disease (WLD) is a commonly observed lesion and has frequently been reported as a major cause of lameness, particularly where cattle are housed, fed concentrates and higher yielding (Collick et al., 1997; Amory et al., 2008; Kujala et al., 2010). Economic losses associated with this lesion include decreased milk production, weight loss, reduced fertility, treatment costs and premature culling (Collick et al., 1997; Green et al., 2002; Hashemi et al., 2005; Amory et al., 2008; Nouri et al., 2008a).

In general, the term white line disease refers to the conditions of haemorrhage, fissure and abscess, which may occur at the white line zone, usually the outer claw of the hind foot (often both) is usually involved (Greenough, 2007). Bacterial WL phlegmon renders cows lame and poses a marked problem in dairy herds in Iran. In addition, nearly all haemorrhages are indicators of subclinical laminitis, although they are supposed to have different origin in the WL and sole areas (Mulling, 2002; Lischer et al., 2002; Offer et al., 2003). Weakening of the WL and disturbances in horn production caused by laminitis (haemorrhages) have been suggested to underlie WLD, although WLD might also present as a primary disease (Mulling, 2002). Several Iran reports cite the condition as responsible for between 1.53 and $27.14 \%$ of lameness (Meimandi-Parizi and Eskandari, 1996; Mansouri-Nejad et al., 2011; Nouri et al., 2011). Other studies also have reported the disease between 5.5 and 39.0\% (Eddy and Scott, 1980; Choquetta-Levy et al., 1985; Tranter and Morris, 1991; Collick et al., 1997; Hedges et al., 2001; Manske et al., 2002; Sogstad et al., 2005; Kujala et al., 2010).

Corresponding Author: Mohsen Nouri, Department of Clinical Sciences, Faculty of Veterinary Medicine, The University of Tehran, P.O. Box 14195-181, Tehran, Iran Tel: + 982188066331 Fax: 66933222 
Although laminitis is generally regarded as the primary cause for the pathological changes within the white line region of the sole, other contributing factors should be considered. In this study, emphasis will be placed on the more advanced condition of white line abscess. The aim of this study was to investigate and quantitate pathomorphological findings of white line disease in culling lame cows, with special reference to the lesions and their distribution.

\section{MATERIALS AND METHODS}

\subsection{Animals}

This cross-sectional and descriptive study was carried out in the winter of the year 2010 at an abattoir in the vicinity of Tehran (Meysam, Robatkarim). During the three- month period of investigation, 53 culled lame cows of 1135 culled Holstein cows having digit disorders were randomly selected for clinical and pathomorphological purpose. The owners were interviewed using a questionnaire to record information about culled lame cow. All cases aged three to eight years.

Lameness was assessed by means of a visual locomotion score (1-5). Each animal was observed standing and walking (on a concrete surface whenever possible) by an experienced technician. Both front legs and hind legs were amputated at the carpus and the tarsus, respectively, immediately after slaughter.

\subsection{Radiographic Examination}

The claws and interdigital space cleaned thoroughly with water and a brush before radiography to be able to exactly diagnose the kind of injury in the radiographic images. An x-ray machine was used in this study (Toshiba, model DC-12M) to take radiographic images. In every case at least two radiographs of lateromedial or mediolateral and dorsopalmar/dorsoplantar, were taken using exposure factors of $25 \mathrm{~mA}, 85-95 \mathrm{KV}$ in 0.04 or 0.02 sec. Radiographs were recorded by the mammography cassettes in sizes of $18 \times 24$ and $24 \times 30$.

\subsection{Pathologic Examination}

For availability and study of the probable changes in soft tissues, the skin of digit was dissected in each sample by a scalpel. The bones were taken away from the joints by the scalpel in order to be naked. Through the method of putrefaction (bacterial maceration and bleaching), the bones were put in a special dish (a plastic cover). In this regard, some plastic dishes with sufficient water were used and placed near the heater. The bones were in the water for at least $72 \mathrm{~h}$ and this action repeated again after changing the old water. Thus, all the soft tissues were taken away from the bones. All the samples were disinfected by diluted disinfectant $\left(\right.$ Vaytex ${ }^{\circledR}$ ) for 30 minutes and the existing tiny tendons and ligaments beside the new bones were taken away slowly and delicately by the scalpel. Then, the bones became dried in free air and prepared for the pathological study. Finally, the findings were discussed descriptively.

\section{RESULTS}

\subsection{Clinical Findings}

Sixteen cases out of the total of 53 cases $(30.1 \%)$ were affected by WL lesions; 7 cases (13.2\%) and 9 cases $(16.9 \%)$ were affected with WLD 2 and WLD 3, respectively. The prevalence rate of WL lesion in the hind limb $(75.0 \%)$ was higher than fore limb. Affected cows were lost their weight significantly and preferred to lie. The animals were severely lame and presented with disability in weight bearing. Locomotion scoring assessment (1-5) of the case showed score 5 ( of $5=$ non-weight bearing) lameness.

The affected limb associated with a painful, firm and focal inflammatory swelling of the bulb heel (Fig. 1) and periople part was distended. The affected claws were more boxy than normal and the abaxial wall was convex in all directions. The opening of the claws was asymmetric. In some cases, the region proximal to the dorsal coronary band was erythematous. Some cases showed widening of the axial and abaxial laminar zone. In all cases, the horn of the WL zone was lost and result to be established of oval or circular perforation. Eight cases have been trimmed incorrectly and other had no natural wearing on the solar surface and showed an increase in thickness of the keratinized tissues.

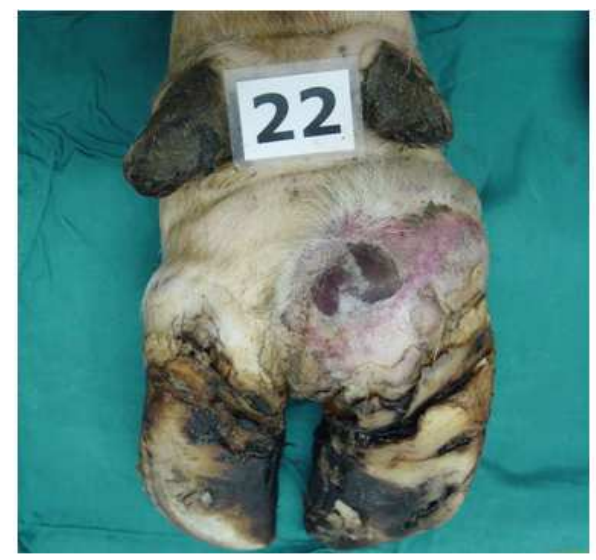

Fig. 1. The heel bulb on the lateral digit is wider than the medial digit. This sign in the involved digital were the permanent features of the culled lame cows with deep sepsis of digit bones 

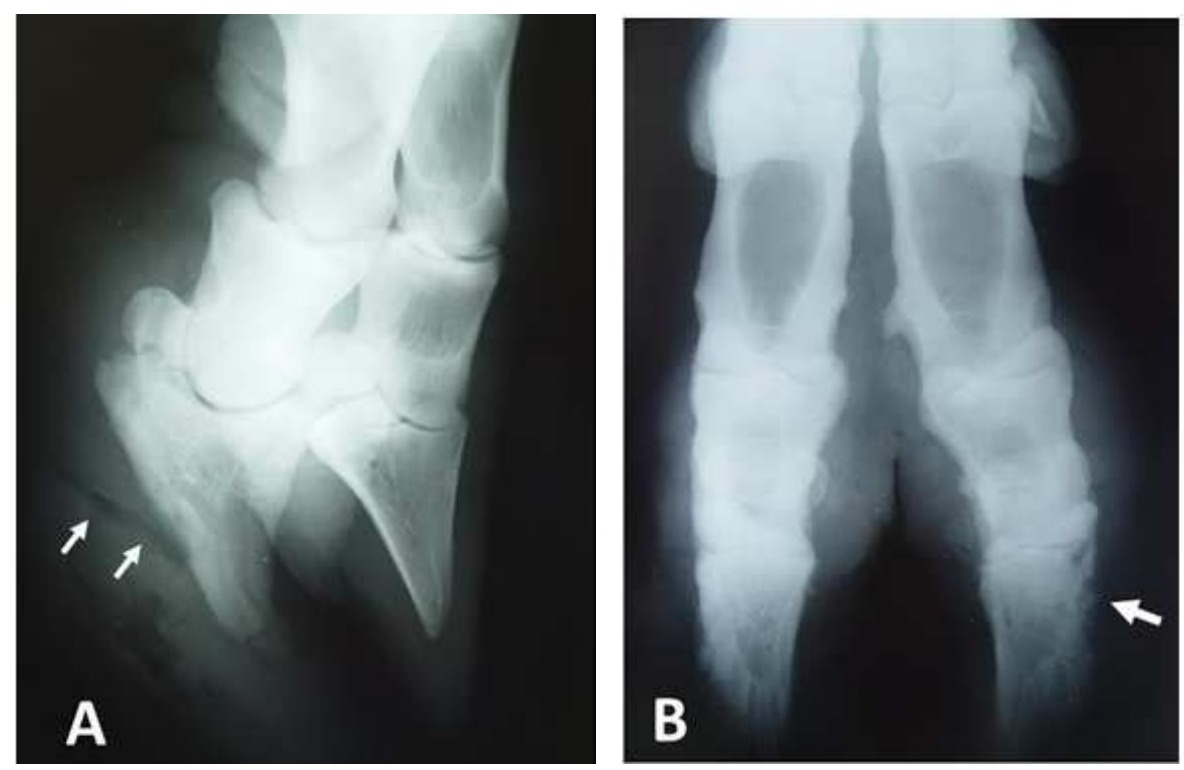

Fig. 2. (A) Dorsolateral-plantomedial oblique view of abaxial margin bone absorption is seen on the abaxial wall of $P 3$ bone (white arrow). Gas density (white arrows) into the claw is present. (B) Dorsoplantar view of the affected digit by WLD2 showing osteo
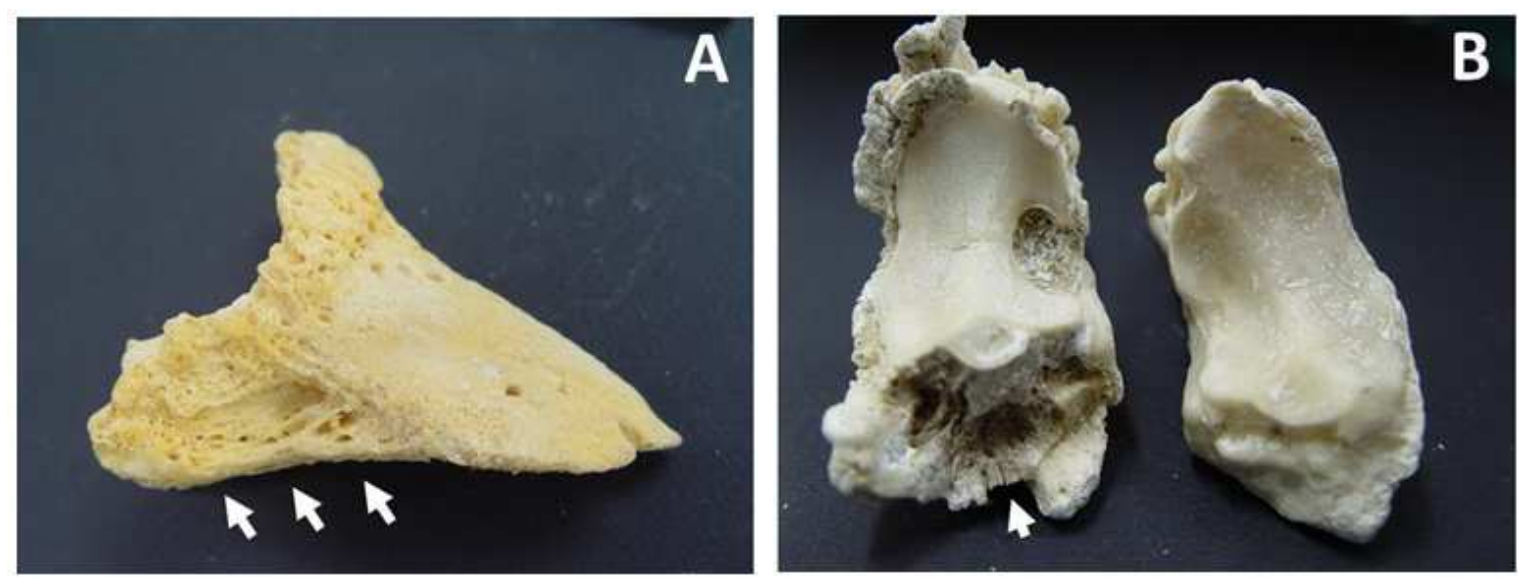

Fig. 3. (A) Lateral view of the affected digit by WLD2 showing osteomyelitis on the abaxial wall of P3 bone (white arrows). (B) Caudal view of the affected digit by WLD3 showing osteolysis of flexor tuberisity of P3 bone (white arrow)

\subsection{Radiographic Findings}

Radiographic signs such as soft tissue swelling, new bone formation, osteitis and gas density were distributed in different sizes; they were more significant considering the increased infection and the involvement of other neighboring structures, such as coffin's joint and the adjoining digit bones. Radiological examinations showed chronic lesions of WLD were accompanied by alterations in the anatomical structure of third phalanx such as abaxial margin bone absorption, flexor tuberisity entheseophyte, extensor process entheseophyte and widened vascular channel (Fig. 2).

\subsection{Pathologic Findings}

The necropsy procedure revealed tendovaginitis and the consistent purulent discharge was confined to the digital region. Affected digits of the culled lame cows with WLD depicted a quite wide range of pathologic 
signs. The naked bone showed considerable bone changes such as excessive new bone formation, osteolysis, ankylosis and sequestration; Eleven out of the total of WLD cases showed abaxial margin bone absorption $(68.7 \%)$ and also 6 out of the total of WLD3 cases had osteolysis of flexor tuberisity (66.7\%) (Fig. 3A and B). In WLD3 cases, three out of the total of 9 cases showed septic osteoarthritis in distal inter-phalangeal joint (33.3\%). In most cases chronic osteophytes of extensor tendon was seen at insertion on the extensor process (75.0\%), but only three cases $(37.5 \%)$ showed calcification of the deep flexor tendon on P3 bone. Ankylosis was observed only in one case between P3 bone and distal sesamoid bone. One of case with WLD2 showed severe bone sequestration of P3 bone. Four mild cases (25.0\%) were concurrent lesion for contralateral claw.

\section{DISCUSSION}

The pathogenesis of white line disease has never been demonstrated conclusively (Greenough, 2007). It is postulated that there are two possible pathologies: A lesion caused by external trauma (The open hypothesis) and another one caused as the result of the collapse of the pedal bone support system and this could result in lateral pressure on the abaxial wall. In this way the white line could be torn open from the inside (The closed hypothesis) (Greenough, 2007). Breed, parity, housing type, hard surfaces, soft horn as a result of wet conditions, claw deformities, age, milk yield, routine claw trimming, chronic laminitis and excessive road work all have been associated with white line disease (Collick et al., 1997; Hedges et al., 2001; Green et al., 2002; Manske et al., 2002; Livesey et al., 2003; Potzsch et al., 2003; Hultgren et al., 2004; Tomlinson et al., 2004; Sogstad et al., 2005; Greenough, 2007; Amory et al., 2008; Kujala et al., 2010).

Most white line disease cases were located in the posterior part of the outer wall of the lateral hind claw (Zone 3). The abaxial border of the sole is the area of first impact in locomotion (Edwards, 1980). The WL is anatomically susceptible (weak laminae region (especially in zone 3) and different horn production in different parts of WL) to mechanical disturbances, which could explain the deleterious association of the slats (Mulling, 2002; Sogstad et al., 2005; Kujala et al., 2010).

Widening of the periople (Nouri et al., 2008b) and swelling of the heel area (Van Meter et al., 2005; Nouri et al., 2008b; Collick et al., 1997; Greenough,
2007) occurs when a deep sepsis of digital bones is present. These cases showed both of signs.

In most cases chronic osteophytes of extensor tendon was seen at insertion on the extensor process, but only three cases $(37.5 \%)$ showed calcification of the deep flexor tendon on P3 bone. Abnormal weight bearing and claw conformation effect on the excessive traction on the tendon. Hashemi et al. (2005) studied the radiographic appearance of lame cows with signs of white line disease. The most prominent radiographic abnormalities of the claw artery included vascular dilations (90\%), extensor process entheseophyte $(80 \%)$, flexor tuberisity entheseophyte $(40 \%)$ and solar margin bone absorption (45\%). Mansouri-Nejad et al. (2011) found sub-solar abscess in zone 3 progressed to the septic osteitis of the third phalanx with osseous sequestration in $14.2 \%$ cases.

Pedal osteolysis was found on the abaxial wall of P3 bone of the affected claw with WLD2. This sign is due to the persistence of the external lesion (Moldovan et al., 1990). Once the corium of the WLD2 was exposed, infection to penetrate in the white line and drove upwards to cause a septic laminitis (Edwards, 1980). The infection track upwards, eventually ending in pedal osteolysis on the abaxial wall of P3 bone and flexor tuberisity. The osteolysis and pedal osteitis in the region of the laminae at the dorsal edge of P3 bone are considered signs of laminitis (Bargai, 1989). In grosspathologic study of naked bone, pedal osteolysis was found on the abaxial margin of the P3 bone. However, other radiographic studies have reported pedal osteolysis on the solar margin bone (Gantke et al., 1998; Hashemi et al., 2005).

Infection of the Distal Interphalangeal Joint (DIJ) usually results from localised purulent processes that spread to the deeper structures of the claw, such as White Line Disease (WLD) (Heppelmann et al., 2009). In the majority of cases with infection of the DIJ, other adjacent anatomical structures, including the Deep Digital Flexor (DDF) tendon, the podotrochlear bursa and the flexor tendon sheath are affected as well as the distal sesamoid bone and the middle (P2) and distal Phalanges (P3), which form the joint (Heppelmann et al., 2009). In our study, $33.3 \%$ out of the total of WLD3 cases showed septic osteoarthritis in distal inter-phalangeal joint.

Involvement of the tendon is uncommon in WLD cases (Collick et al., 1997). Advanced cases had tendon involvement in this study. In these cases, sepsis of the digital flexor tendon sheath (septic tendovaginitis) occurred as a result of extension of local sepsis.

Improper hoof trimming techniques may result in traumatic laminitis (Enevoldsen and Grohn, 1991); at least 
if the trimmer takes away supportive mechanism of the horn with a grinder or the sole becomes too thin during trimming (Kujala et al., 2010). This case showed increase of solar layer without any sign of trimming. Trimming therefore could not be responsible for WLD in our study.

In this study clinical lameness was observed and managed by the farmer. It is likely, given previous research that indicated that farmers did not detect all cases of lameness (Whay et al., 2002), that some cows were treated inappropriately and so no diagnosis and or misdiagnosis were made (Amory et al., 2008; Nouri et al., 2008a). There were certainly some lame cows on the farm at routine visits assessing locomotion (Barker et al., 2007).

\section{CONCLUSION}

The results of the present study indicate that laminitis may have affected virtually this case at some previous time. Routine trimming and scoring of locomotion seems to provide suitable parameters for early diagnosis and prevention of premature culling in dairy cows.

\section{ACKNOWLEDGMENT}

The slaughterhouse staff is acknowledged for their assistance in the preparation of abattoir specimens. The authors are particularly indebted to Dr. Afshin Motaghifar (the Chief meat inspector in Meysam Slaughterhouse, RobatKarim road) for supporting this study. This study was funded by Faculty of Veterinary Medicine, the University of Tehran (Tehran, Iran).

\section{REFERENCES}

Amory, J.R., Z.E. Barker, J.L. Wright, S.A. Mason and R.W. Blowey et al., 2008. Associations between sole ulcer, white line disease and digital dermatitis and the milk yield of 1824 dairy cows on 30 dairy cow farms in England and Wales from February 2003-November 2004. Prev. Vet. Med., 83: 381391. DOI: 10.1016/j.prevetmed.2007.09.007

Bargai, U., 1989. Radiological Diagnosis of the Foot. In: Bovine Radiology. Bargai, U., J. Pharr, J.P. Morgan (Eds.), John Wiley and Sons, Ames, ISBN-10: 0813801850, pp: 29-64.

Barker, Z.E., J.R. Amory, J.L. Wright, S.A. Mason and R.W. Blowey et al., 2007. Management factors associated with impaired locomotion in dairy cows in England and Wales. J. Dairy Sci., 90: 3270-3277. DOI: $10.3168 /$ jds.2006-176
Choquetta-Levy, L., J. Baril, M. Levy and H. St-Pierre, 1985. A study of fool disease of dairy cattle in Quebec. Can. Vet. J., 26: 278-281.

Collick, D.W., AD. Weaver and P.R. Greenough, 1997. Interdigital Space and Claw. In: Lameness in Cattle. Greenough, P.R. (Ed.), Saunders, Philadelphia, ISBN-10: 0721652050, pp: 101-107.

Eddy, R.G. and C.P. Scott, 1980. Some observation on the incidence of lameness in dairy cattle in Somerset. Vet. Rec., 106: 140-144. DOI: 10.1136/vr.106.7.140

Edwards, G.B., 1980. White line disease of the foot in cattle. Vet. Annu., 20: 227-232.

Enevoldsen, C. and Y.T. Grohn, 1991. Heel erosion and other interdigital disorders in dairy cows: Associarions with season, cow characteristics, disease and production. J. Dairy. Sci., 74: 12991309. DOI: $10.3168 /$ jds.S0022-0302(91)78285-4

Gantke, S., K. Nuss and R. Kostlin, 1998. Radiologic findings in bovine laminitis. Tierarztl. Prax. Ausg. G. Grosstiere. Nutztiere., 26: 239-246. PMID: 9810600

Green, L.E., V.J. Hedges, Y.H. Schukken, R.W. Blowey and A.J. Packington, 2002. The impact of clinical lameness on the milk yield of dairy cows. J. Dairy Sci., 85: 2250-2256. DOI: $10.3168 /$ jds.S00220302(02)74304-X

Greenough, P.R., 2007. Bovine Laminitis and Lameness. 1st Edn., Elsevier Science Health Science Division, ISBN-10: 0702027804, pp: 311.

Hashemi, M., A. Veshkini and I. Nowrouzian, 2005. Radiographic feature of white line disease in dairy cattle. Proceedings of the 4th Convention of Iranian Veterinary Clinicians, May 31-Jun. 2, Urmia, Iran, pp: 175-176.

Hedges, V., R.W. Blowey, A.J. Packington, C.J. O'Callaghan and L.E. Green, 2001. A longitudinal field trial of the effect of biotin supplementation on lameness in dairy cows. J. Dairy Sci., 84: 19691975. DOI: 10.3168/jds.S0022-0302(01)74639-5

Heppelmann, M., J. Kofler, H. Meyer, J. Rehage and A. Starke, 2009. Advances in surgical treatment of septic arthritis of the distal interphalangeal joint in cattle: A review. Vet. J., 182: 162-175. DOI: 10.1016/j.tvj1.2008.06.009

Hultgren, J., T. Manske and C. Bergsten, 2004. Associations of sole ulcer at claw trimming with reproductive performance, udder health, milk yield and culling in Swedish dairy cattle. Prev. Vet. Med., 62: 233-251. DOI: 10.1016/j.prevetmed.2004.01.002 
Kujala, M., I.R. Dohoo and T. Soveri, 2010. White-line disease and haemorrhages in hooves of Finnish dairy cattle. Prev. Vet. Med., 94: 18-27. DOI: 10.1016/j.prevetmed.2009.12.006

Lischer, C., P. Ossent, M. Raber and H. Geyer, 2002. Suspensory structures and supporting tissues of the third phalanx of cows and their relevance to the development of typical sole ulcers (rusterholz ulcers). Vet. Rec., 151: 694-698. PMID: 12503788

Livesey, C.T., J.A. Metcalf and RA. Laven, 2003. Association of concentrate composition and cubicle bedding on the development of hoof haemorrhages in Holstein heifers after calving. Vet. Rec., 152: 735-739. DOI: $10.1136 /$ vr.152.24.735

Manske, T., J. Hultgren and C. Bergsten, 2002. Prevalence and interrelationships of hoof lesions and lameness in Swedish dairy cows. Prev. Vet. Med., 54: 247-263. DOI: 10.1016/S0167-5877(02)00018-1

Mansouri-Nejad, S.E., A. Ahmadpanah, F. Katoli, F. Zibaee and I. Nowrouzian, 2011. A case series study of white line disease in dairy cows: Complication and consequences. Proceedings of the 16th International Symposium and 8th Conference on Lameness in Ruminants, Feb. 28-Mar. 03, Rotorua, New Zealand, pp: 158.

Meimandi-Parizi, A. and A. Eskandari, 1996. Prevalence of lameness in dairy and beef cattle of Marvdasht area during the winter. Scient. Inform. Datab., 35: 115-119.

Moldovan, M., S. Bolte and C. Igna, 1990. Radiological research on the phalangeal changes in pododermatitis circumscripta in cattle. Proceedings of the 6th International Symposia on Diseases of the Ruminant Digital Liverpool, (RDL' 90), UK., pp: 269-275.

Mulling, C., 2002. Theories on the pathogenesis of white line disease-an anatomical perspective. Proceedings of the 12th International Symposium on Lameness in Ruminants, Jun. 9-13, Orlando, FL, USA., pp: 90-98.

Nouri, M., A. Vajhi, I. Nowrouzian, S.H. Marjanmehr and D. Faskhoudi, 2008b. "Rusterholz" ulcer in culling lame cows: Clinical and radiographic interpretation. Iran. J. Vet. Surg., 3: 29-36.
Nouri, M., I. Nowrouzian, A. Vajhi, S.H. Marjanmehr and D. Faskhoudi, 2011. Morphometric radiographic findings of the digital region in culling lame cows. Asian J. Anim. Sci., 5: 256-267. DOI: 10.3923/ajas.2011.256.267

Nouri, M., I. Nowrouzian, S.H. Marjanmehr and H. Shad, 2008a. Lameness in cattle: Misdiagnosis or inappropriate therapy? Scient. Inform. Datab., 79: 186-192.

Offer, J.E., K.A. Leach, S. Brocklehurst and D.N. Logue, 2003. Association of forage type on claw horn lesion development in dairy heifers. Vet. J., 165: 221-227. DOI: 10.1016/S1090-0233(02)00171-5

Potzsch, C.J., V.J. Collis, R.W. Blowey, A.J. Packington and L.E. Green, 2003. The impact of parity and duration of biotin supplementation on white line disease lameness in dairy cattle. J. Dairy Sci., 86: 2577-2582. DOI: $\quad 10.3168 /$ jds.S00220302(03)73852-1

Sogstad, A.M., T. Fjeldaas, O. Osteras and K.P. Forshell, 2005. Prevalence of claw lesions in Norwegian dairy cattle housed in tie stalls and free stalls. Prev. Vet. Med., 70: 191-209. DOI: 10.1016/j.prevetmed.2005.03.005

Tomlinson, D.J., C.H. Mulling and T.M. Fakler, 2004. Invited review: Formation of keratins in the bovine claw: Roles of hormones, minerals and vitamins in functional claw integrity. J. Dairy Sci., 87: 797-809. DOI: $10.3168 /$ jds.S0022-0302(04)73223-3

Tranter, W.P. and R.S. Morris, 1991. A case study of lameness in three dairy herds. N.Z. Vet. J., 39: 8896. DOI: 10.1080/00480169.1991.35668

Van Meter, D.C., J.R. Wenz and B.F. Garry, 2005. Lameness in Cattle: Rules of tumb. Proc. Am. Assoc. Bovine Pract., 38: 40-43.

Whay, H.R., D.C.J. Main, L.E. Green and A.J.F. Webster, 2002. Farmer perception of lameness prevalence. Proceedings of the 12th International Symposium on Lameness in Ruminants, (SLR' 02), Orlando, USA., pp: 355-358. 